Artículos/ Articles

\title{
Desarrollo industrial, trabajo y migración: el caso del norte de Marruecos
}

\author{
Industrial development, labour and migration: the case of \\ northern Morocco
}

\author{
Francisco Barros Rodríguez* \\ Universidad de Jaén, España. \\ fbarros@ujaen.es \\ Rosa M. Soriano Miras (iD) \\ Universidad de Granada, España. \\ rsoriano@ugr.es
}

Antonio Trinidad Requena

Universidad de Granada, España.

atrinida@ugr.es

Recibido / Received: 01/07/2020

Aceptado / Accepted:06/05/2021

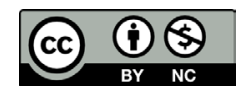

\section{RESUMEN}

El norte de la región marroquí de Tánger-Tetuán-Alhucemas ha contemplado en las últimas décadas un extraordinario crecimiento de su tejido industrial, especialmente mediante el asentamiento de numerosas Empresas Manufactureras de Exportación. Estas empresas se caracterizan por un uso intensivo del factor trabajo y una flexibilidad en las condiciones laborales. Sobre este contexto, el artículo analiza las prácticas sociolaborales implementadas por las Empresas Manufactureras de Exportación y su relación con la decisión de emigrar al extranjero (o no) por parte de sus trabajadores. Para ello se ha implementado un estudio analítico-interpretativo, el cual ha contado con 93 entrevistas en profundidad a trabajadores del sector industrial. Siguiendo la Teoría Fundamentada como metodología de análisis, los resultados muestran cómo las Empresas Manufactureras de Exportación han tenido una importante incidencia en la cultura migratoria de los trabajadores y, en concreto, en su búsqueda del bienestar a través de la migración.

Palabras clave: Desarrollo industrial, empresa manufacturera de exportación, cultura migratoria, marruecos, condiciones laborales. 


\begin{abstract}
The north of the Moroccan region of Tangier-Tetouan-Al Hoceima has seen an extraordinary growth in its industrial fabric in recent decades, especially through the establishment of numerous Export Manufacturing Companies. These companies are characterized by an intensive use of the work factor and flexibility in working conditions. In this context, the article analyzes the social and labor practices implemented by Export Manufacturing Companies and their relationship with the decision to migrate abroad (or not) by their workers. For this, an analytical-interpretive study has been carried out, which has used 93 in-depth interviews with workers in the industrial sector. Following the Grounded Theory as an analysis methodology, the results show how Export Manufacturing Companies have had an important impact on the migratory culture of workers and, specifically, in their search for well-being through migration.
\end{abstract}

Keywords: Industrial development, export manufacturing company, migratory culture, morocco, working conditions.

\title{
INTRODUCCIÓN
}

El área más septentrional de la región marroquí de Tánger-Tetuán-Alhucemas, la península tingitana, ha contemplado en las últimas décadas una serie de acontecimientos que la han conformado en un importante espacio industrial transfronterizo a nivel global (Soriano et al., 2015). Si bien su actividad económica estuvo tradicionalmente orientada hacia el sector primario, desde hace años la industria y el comercio han experimentado un extraordinario crecimiento. El principal precedente de esta transformación se halla en el Programa de Ajuste Estructural (PAE), aplicado entre 1983 y 1993, y que tuvo como finalidad la liberalización comercial de Marruecos y su incorporación en las Cadenas Globales de Valor (CGV). Los procesos productivos, que permanecen integrados y conectados en red, se han segmentado geográficamente (Bianchi y Szpak, 2013) con el objetivo de maximizar los beneficios de las empresas manufactureras de exportación (EME). Mientras China (y algunos países del Sudeste Asiático) se ha convertido en la fábrica del mundo y la India en el back office del planeta, otros países como Marruecos se han centrado en la producción de mercancías que requieren líneas de suministro más cortas (Gereffi y Sturgeon, 2013). El estratégico emplazamiento del norte de Marruecos, que ofrece unos menores costes de exportación hacia los lugares de consumo (clave para los sistemas de producción just in time), ha permitido que la región cuente hoy con cerca de 1.000 empresas del sector industrial, las cuales emplean a más de 100.000 trabajadores y exportan el $70,3 \%$ de su producción (Haut-Commissariat au Plan, 2016a). En el caso específico de las ramas industriales del textil y la eléctricaelectrónica, con gran presencia en la región, el volumen exportado asciende hasta el $98,8 \%$ y el $76,8 \%$ respectivamente.

El aumento de la influencia industrial en la economía regional se halla vinculado con otro proceso social: su reconfiguración sociodemográfica y, en particular, su establecimiento como espacio migratorio transfronterizo (Hennebry et al., 2014). La apuesta estatal por el desarrollo industrial ha actuado como elemento atrayente de flujos migratorios internos hacia las grandes urbes, los cuales aspiran a lograr un empleo en las EME con el que promocionar socialmente, mejorar sus condiciones de vida y acceder a nuevos bienes de consumo. La demanda de mano de obra por parte de estas empresas ha influido en la percepción subjetiva de la migración entre 
la población, especialmente entre los más jóvenes (Solís y Castañeda, 2013), tanto en las zonas rurales de la propia región como en otras menos prósperas del país e, incluso, internacionales. El crecimiento poblacional urbano de la región entre 1994 y 2014 ha sido del 74,6\%, alcanzándose los cerca de 2 millones de habitantes censados (Haut-Commissariat au Plan, 2016b). La movilidad hacia Tánger o Tetuán, sin embargo, se ha constituido en una antesala de la emigración internacional (Capote, 2014), a la cual se incorpora la población autóctona. La gobernanza pública marroquí, en su afán por atraer inversores extranjeros a la región, ha optado por una actitud laxa en el cumplimiento de la legislación laboral (Trinidad et al., 2018). Ello ha supuesto una precarización general de las condiciones de trabajo en el sector industrial y, por extensión, una acentuación de la cultura migratoria presente en el norte de la región (Trinidad et al., 2015).

Sobre este escenario, el artículo se interroga por el papel que las EME asentadas en el norte de Marruecos juegan en la cultura migratoria: Marruecos cuenta con una comunidad en el extranjero de entre 4 y 5 millones de personas (Berriane, 2018), la cual supone el $8-10 \%$ del total poblacional, y que continúa aumentando tanto por las nuevas contribuciones migratorias como por las pautas de natalidad en el lugar. En concreto propone estudiar los factores asociados a las prácticas sociolaborales implementadas por las EME de la región de Tánger-Tetuán-Alhucemas y la decisión de emigrar internacionalmente (o no) de sus trabajadores. Para ello se ha llevado a cabo una investigación que parte de la entrevista en profundidad como técnica de producción de datos y de la teoría fundamentada como técnica de análisis. En total se han realizado 93 entrevistas a trabajadores del sector industrial. En respuesta al propósito planteado, el artículo se inicia con una revisión teórica en torno al desarrollo industrial y el fenómeno migratorio en Marruecos. Posteriormente se atienden los aspectos metodológicos que han orientado el trabajo, así como los principales resultados del mismo. Se cierra el artículo con un apartado de conclusiones.

\section{Desarrollo industrial y cultura migratoria}

El concepto de «cultura migratoria» surge en contraposición a los trabajos que explican los procesos migratorios en base a incentivos meramente económicos y que, por tanto, no ofrecen una elucidación válida a cuestiones tales como que, en una misma comunidad, sujetos con similares recursos y presiones económicas opten por emigrar y otros no (Cohen y Sirkeci, 2011). Entre los estímulos que intervienen en la decisión migratoria, el componente económico cumple un papel relevante pero insuficiente: necesita de un componente sociocultural que lo complemente. Con cultura migratoria se hace alusión al proceso de socialización a partir del cual los miembros de una comunidad comparten un conjunto de actitudes, creencias y valores referentes al fenómeno migratorio. Sería el habitus existente en el imaginario de los actores mediante el cual se perciben y evalúan colectivamente las prácticas migratorias (Bourdieu, 2012).

Las acepciones que ponen el acento en la intersubjetividad que produce dicho habitus, no obstante, son diversas y generalmente se hallan en conflicto. Diferenciamos entre una cultura migratoria "centrífuga» (si promueve la emigración) o "centrípeta» (si estimula el arraigo comunitario) según: los impactos de la migración en la familia y la comunidad de origen (Hawkins et al., 2010), los obstáculos y riesgos del proceso migratorio (Ojeda y Espinosa, 2010), el sentido de pertenencia territorial y el apego a la familia (Gendreau y Giménez, 2002), el valor de la educación como estrategia de movilidad social (Echeverría y Lewin-Fischer, 2016), las oportunidades económicas y legales en destino (Engbersen et al., 2013), las normas culturales asociadas al género y la edad (Mata, 2015) o el desarrollo industrial (Hennebry et al., 2019). 
Los primeros trabajos interesados en la relación entre desarrollo y migración se centraron en el caso de la maquiladora mexicana. La mayoría de autores (Bustamante, 1983; Fernández-Kelly, 1983; Seligson y Williams, 1981) coincidían en que la instalación de la industria maquiladora a lo largo de la frontera mexicana con Estados Unidos no contribuía a la migración internacional, sino que proporcionaba un empleo para todos aquellos trabajadores agrícolas que regresaban de territorio estadounidense tras la finalización en 1964 del Mexican Farm Labor Program (programa Bracero). Frente a esta idea, por la cual la migración se ralentizaría con el progresivo desarrollo mexicano, Portes (1979) defendía una postura contraria. Según este autor la migración laboral no se produce por la pobreza y el atraso económico del país, sino por su rápido desarrollo. Este proceso incide en los siguientes escenarios: a) la población rural, muy numerosa, se desliga del campo sin disponer de un empleo alternativo; b) el crecimiento económico se produce simultáneamente a un aumento de la distribución desigualitaria de la riqueza; c) la población absorbe un moderno culto al consumo, a la vez que le son negados los medios para participar de él; y d) el control de la industria pasa a manos de propiedad extranjera. Como reforzaría Castles (2004), los procesos de industrialización incrementan, en lugar de disminuir, la presión migratoria sobre la clase obrera.

En las siguientes décadas aparecieron algunos estudios (Barajas y Martínez, 2013; Carrillo, 1990; Fussell, 2004; Mendoza, 2011; Zabin y Hughes, 1995) que mantenían una posición cercana a Portes: aunque reconocían que las fábricas eran una importante fuente de empleo, no disuadían las intenciones migratorias de sus trabajadores. Revelaron que muchos mexicanos que habían emigrado desde el interior del país para emplearse en las maquiladoras, posteriormente se embarcaban en un nuevo proceso migratorio hacia Estados Unidos. Estos estudios, sin embargo, no alcanzaron a confirmar una relación directa entre desarrollo industrial y migración internacional.

Literatura más reciente (Kopinak, 2011; Kopinak y Soriano, 2013), que ha recurrido ocasionalmente a análisis comparativos entre la realidad mexicana y marroquí(Kopinak et al., 2013), ha demostrado que si bien la industria no fomenta intencionalmente la migración internacional de sus trabajadores, sí ayuda indirectamente a obtener la documentación necesaria para emigrar legalmente. Hennebry et al. (2019) incluso afirman que, en el caso tijuanense, el proceso migratorio se simplifica para aquellos trabajadores cualificados y con cierta responsabilidad en la empresa: estos suelen comunicarse de manera regular con altos cargos de la compañía, los cuales les brindan ayuda en su solicitud de empleo en Estados Unidos. Solís (2010), por su parte, ha observado cómo algunas mujeres, tanto en Tánger como Tijuana, deciden emplearse en la industria como parte de un plan para emigrar internacionalmente a largo plazo. Las fábricas industriales, en definitiva, se han convertido en actores clave del sistema migratorio en estas áreas fronterizas del norte de México y Marruecos.

En el caso del país alauí, la cultura migratoria se ha constituido como parte esencial de su historia reciente. Los años del Protectorado francés dotaron a Marruecos de sus primeras industrias (por ejemplo, minas de fosfato), de infraestructuras de transporte terrestre o de tierras de regadío (hasta ese momento de secano). Sin embargo, también confirieron problemas de gran envergadura como la creación de grandes latifundios en propiedad de pocas familias adineradas (muchas europeas), una altísima tasa de analfabetismo o una pésima organización de las grandes urbes a raíz de una primera emigración rural-urbana (Barros, 2017). Los flujos migratorios internacionales, aunque importantes durante la época colonial, se acentuaron en las décadas posteriores a la independencia de Marruecos en 1956, especialmente hacia Europa occidental y central (De Haas, 2007).

En estos años se puso en marcha un proceso de Marroquinización de la economía, pasando muchos sectores a estar controlados por el Estado, y se creó un programa 
de inversión con el que impulsar las exportaciones agrícolas. Pero ninguna de estas políticas resultó satisfactoria. La inestabilidad económica provocó un crecimiento descontrolado de las grandes urbes, emergiendo las denominadas bidonvilles, y un aumento de los flujos migratorios a Francia, antigua metrópoli, y más tarde a Bélgica y Países Bajos. El gobierno marroquí inició entonces una política de estímulo de las migraciones como herramienta de desarrollo (De Haas, 2006), de cara a incentivar tanto las inversiones de los migrantes como las remesas monetarias desde los países de destino. En los 60-70 la transferencia de divisas de los ciudadanos emigrados a Europa "alcanzaron un importante porcentaje de la renta nacional global" (Pennell, 2009 , p. 252), a la vez que modulaban la cultura migratoria de sus habitantes. Stark y Taylor (1989) afirman que las remesas monetarias promueven una desigual distribución de ingresos entre las familias de origen. Estas familias disponen de unos bienes simbólicos que les lleva a distinguirse y situarse más arriba en la jerarquía local, pasando a ser vistas por el resto como "familias de referencia». Las remesas incentivan la sensación de "privación relativa» entre los grupos familiares sin miembros emigrados, constituyéndose como una motivación añadida para la migración. Pero no solo las remesas suponen sentimientos de insatisfacción que impulsan la emigración: Serajuddin y Verme (2015) señalan que la «privación laboral relativa» está fuertemente asociada con el deseo de emigrar entre los jóvenes varones marroquíes.

Pese a la situación existente, el gobierno marroquí siguió durante los 70 y principios de los 80 con una línea continuista de gasto público sustentada en el aumento de la deuda exterior. Este endeudamiento no impidió que se llegara a una situación insostenible, con habituales disturbios y huelgas, un aumento de la inflación y la pobreza o la imposibilidad de pago de la deuda. En estos años, que coincidieron con la crisis del petróleo y el aumento de las limitaciones inmigratorias, algunos países de la cuenca mediterránea (España, Italia) y, en menor medida, de Norteamérica (Canadá, Estados Unidos) pasaron a convertirse en receptores de inmigración marroquí. La diáspora marroquí no dejaba de aumentar, posibilitando conocer "el nivel de vida, los servicios sociales y la libertad política en Europa" (Pennell, 2009, p. 265) a través de las historias de los compatriotas con experiencia migratoria. A ello se sumó la influencia de los medios audiovisuales, especialmente con la "aparición de las antenas parabólicas", que permitían sintonizar con todas las cadenas del Mediterráneo" (Pennell, 2009, p. 266). Estas cadenas prestan mayor atención a las clases sociales adineradas y elitistas, mostrando un retrato limitado y estereotipado de la población a la vez que ensalza la sociedad de consumo europea (García y Verdú, 2008). Igualmente sucede con los propios programas de televisión marroquíes, los cuales presentan mayoritariamente a compatriotas que han tenido éxito en el extranjero (Sadiqi, 2007).

La salida a la crisis económica y social transcurrió por renegociar la deuda y conseguir nuevas ayudas financieras por parte del Fondo Monetario Internacional y el Banco Mundial, las cuales estaban condicionadas a la aplicación del PAE. En las siguientes décadas se estimularía la Inversión Extranjera Directa (IED), se promocionarían las exportaciones y se liberalizarian las importaciones (García y Jordán, 2006). En este contexto expansivo, la presencia de instituciones, organismos y actores transnacionales arraigó fuertemente en el norte del país, alterando la cultura migratoria de sus habitantes: desde la instalación de empresas y centros educativos de propiedad extranjera o la apertura al turismo ${ }^{2}$, hasta el retorno vacacional de los emigrados en Europa. Trinidad et al. (2015) sugieren que la idea de emigrar se retroalimenta mediante el contacto con paisanos cuando regresan por

1 En 2014 el 90,6\% de los hogares urbanos de Tánger-Tetuán-Alhucemas disponían de antena parabólica (Haut-Commissariat au Plan, 2016b).

2 A mediados de los 80 "visitaban Marruecos entre un millón y millón y medio de turistas al año, en su mayoría franceses y españoles" (Pennell, 2009, p. 268). 
vacaciones. En ocasiones quienes retornan estacionalmente, de cara a evitar que su experiencia migratoria sea catalogada como de fracaso, mantienen un discurso en el que se minimizan los obstáculos y se enaltecen los éxitos en el extranjero (Barros, 2017). Según Timmerman et al. (2014), aquellas regiones con mayor representación del componente transnacional será donde más se asiente una cultura migratoria entre sus habitantes.

Pese al desarrollo industrial y la apertura a actores transnacionales, los problemas económicos (desempleo y descenso del Producto Interior Bruto (PIB) per cápita) y sociales (analfabetismo y bidonvilles) continuaron ante la inestabilidad del crecimiento económico, muy dependiente de la agricultura y su climatología, la coyuntura económica europea y las remesas. Asimismo las redes migratorias en el extranjero, entendidas como aquel capital social que ayuda a reducir los costes y riesgos migratorios, no dejaban de aumentar. Estas redes favorecen la llegada de remesas sociales, esto es, ideas y valores culturales provenientes desde Europa y con gran incidencia en las relaciones sociofamiliares. También aportan información (real o ficticia) esencial en la construcción de un imaginario colectivo sobre la región de destino. Dekker y Engbersen (2013), en un estudio que incluye a la población marroquí residente en Países Bajos, han demostrado que las redes sociales virtuales facilitan la migración.

Si bien las reformas estructurales del PAE han continuado marcando las líneas de actuación de la gobernanza pública marroquí, en las últimas décadas se han implementado nuevas iniciativas para atraer la IED, aumentar el empleo y reducir las migraciones: Charte de L'Investissement (1995), Plan Émergence (2005), Pacte National pour l'Émergence Industrielle (2009-2015), Plan d'Accélération Industrielle (2014-2020) o la ampliación del puerto de mercancías Tanger Med (2019). Pese a ello, los avances sociales han sido más tibios. El Índice de Desarrollo Humano de Marruecos (United Nations, 2019a) ha mejorado (0.676), pero aún se sitúa alejado de los principales países receptores de población marroquí (Francia, España e Italia se ubican cerca de 0.9 , mientras Países Bajos y Bélgica lo superan). Si bien la tasa de alfabetización se ha elevado hasta el 69,4\% para los mayores de 15 años (United Nations, 2019a), produciendo un aumento de las expectativas de la población, el gobierno ha sido incapaz de ofrecer una respuesta en forma de empleo a todos aquellos que han accedido al sistema educativo. La reforma del código de familia (Mudawana) en 2004, aunque ha supuesto un progreso en los derechos de la mujer, no suprime el repudio y la poligamia. Y el Código de Trabajo de 2004, que se ampliará más adelante, no ha evitado la precarización general de las condiciones laborales (Trinidad et al., 2018).

Algunos estudios (Aderghal y Berriane, 2013; Engbersen et al., 2013) sugieren que la percepción de una menor desigualdad entre Marruecos y Europa en términos de calidad de los servicios públicos, derechos humanos y democracia, junto a la información de una disminución de oportunidades laborales en Europa por la crisis de 2008, está reduciendo el interés por emigrar entre los jóvenes, especialmente en regiones urbanas y prósperas como Tánger-Tetuán-Alhucemas (Jolivet, 2015). Snel et al. (2016) muestran cómo los inmigrantes marroquíes asentados en Países Bajos recomiendan a sus paisanos a no emigrar. Mientras que unos contemplan la opción de construir un futuro en Marruecos como alternativa a la emigración, otros parecen resistirse. Pese a la nueva imagen de Europa, la mayoría de trabajos (Aderghal, 2014; Berriane, 2014; Timmerman et al., 2014) apuntan a que la emigración continúa siendo considerada como el principal medio para mejorar el bienestar personal y familiar. La Figura 1 muestra cómo, especialmente con la llegada del nuevo siglo, al enérgico aumento del PIB marroquí (estimulado por el aumento de la IED y la instalación de EME) ha ido aparejado un incremento de los flujos migratorios hacia el exterior. La máxima expresión del desarrollo económico de Marruecos en las últimas décadas ha sido el proceso de relocalización de EME en regiones como Tánger-Tetuán-Alhucemas, motivo por el cual el presente trabajo centra su atención en dicha realidad. 
Figura 1. PIB marroquí y migrantes de origen marroquí en el extranjero (1990-2019)

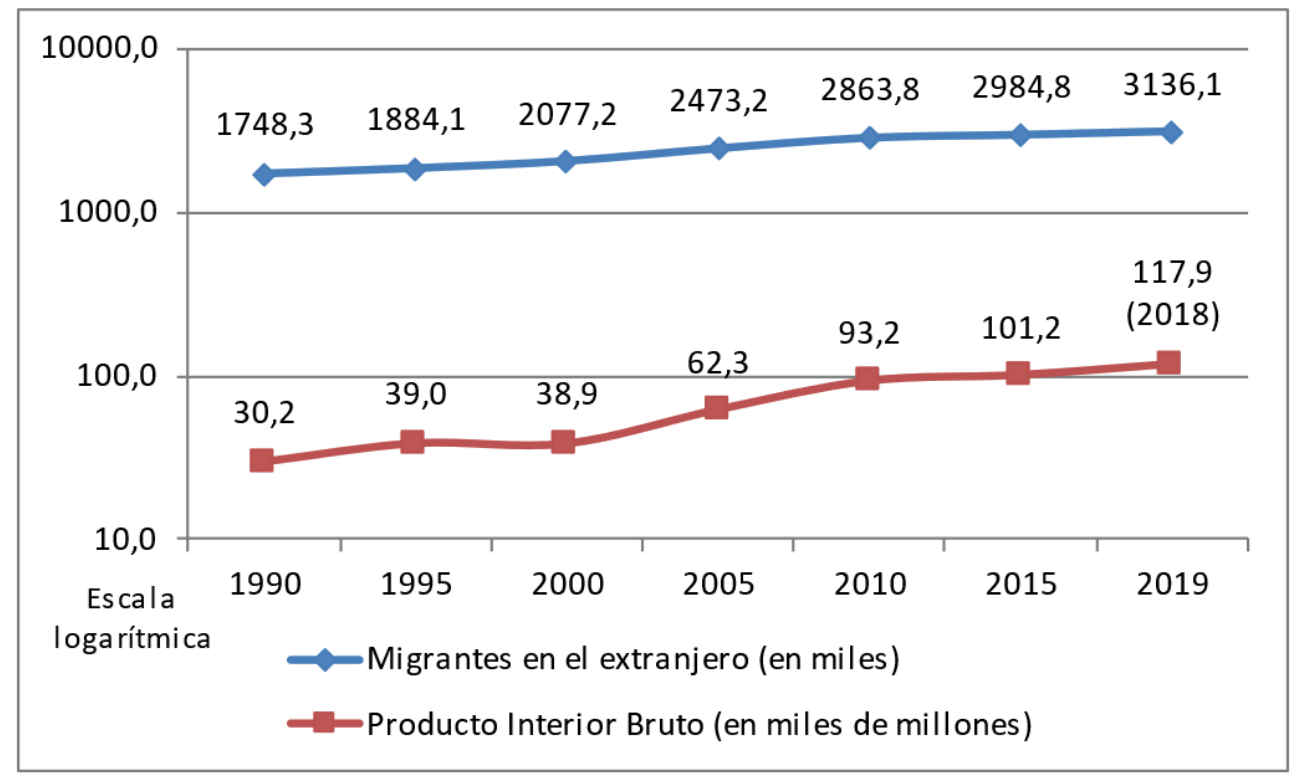

Fuente: Elaboración propia a partir de World Bank (2020) y United Nations (2019b)

\section{CUESTIONES METODOLÓGICAS}

El presente artículo tiene como propósito conocer si el hecho de trabajar en las EME asentadas en el norte de Marruecos influye en la decisión migratoria de sus trabajadores. El trabajo parte de un estudio analítico-interpretativo a través de la realización de entrevistas en profundidad a trabajadores del sector industrial. Esta técnica de recogida de información, apoyada en un guion de preguntas abiertas, fue implementada en diversas ciudades de la región de Tánger-Tetuán-Alhucemas. El principal idioma de las entrevistas fue el däriya (árabe magrebí), por lo que se acudió a la figura de ayudantes lingüísticos.

Para la selección de informantes se recurrió a los criterios de muestreo estructural y saturación teórica, los cuales facilitan un desarrollo conjunto de los procesos de obtención y análisis de la información. En las primeras oleadas de trabajo de campo el muestreo fue abierto en búsqueda de situaciones que ofrecieran información relevante sobre el objeto de estudio. Paulatinamente la investigación fue orientándose hacia determinados informantes que aportaran una mayor variabilidad de categorías: género, edad, nivel educativo, región de procedencia, categoría ocupacional y rama industrial (véase Tabla 1). En el instante en que los datos comenzaron a ser repetitivos se alcanzó la saturación teórica de los discursos y se dieron por finalizadas las fases de muestreo y trabajo de campo. Finalmente se llevaron a cabo cinco oleadas de trabajo de campo entre 2010 y 2015, en las que se realizaron 93 entrevistas en profundidad a trabajadores de EME. A su conclusión se había alcanzado una gran diversidad muestral.

El procedimiento analítico de la información utilizado ha sido la Teoría Fundamentada. Siguiendo esta metodología de análisis, basada en un procedimiento 
inductivo de la información, se realizó un proceso trifásico de codificación ${ }^{3}$ de las entrevistas (Carrero et al., 2012): 1) codificación abierta donde, a partir de la comparación constante de los "incidentes» ${ }^{4}$ encontrados en los relatos de los trabajadores, se hallaron regularidades y singularidades; 2 ) la codificación selectiva donde, una vez que fue identificado el código «respuestas migratorias a la privación relación» como categoría central, la codificación se redujo a aquellas categorías que se relacionan de manera significativa con dicha categoría; y 3) la codificación teórica donde, partiendo de la categoría central, se introdujeron conceptos de mayor nivel de abstracción dentro de la explicación teórica. La tabla 2 sintetiza el procedimiento analítico llevado a cabo, el cual ha derivado en cuatro Procesos Sociales Básicos (sobre los que se han estructurado los subapartados de resultados) y una Categoría Central que explica la mayor variabilidad de los datos.

Tabla 1. Distribución muestral de entrevistas

\begin{tabular}{|c|c|c|c|c|c|}
\hline & & \multicolumn{4}{|c|}{ Rama industrial } \\
\hline & & $\begin{array}{c}\text { Confección y } \\
\text { textil }\end{array}$ & $\begin{array}{l}\text { Automoción y } \\
\text { electrónica }\end{array}$ & Otras & TOTAL \\
\hline \multirow[t]{2}{*}{ Género } & Hombre & 22 & 11 & 22 & 55 \\
\hline & Mujer & 16 & 16 & 6 & 38 \\
\hline \multirow[t]{3}{*}{ Edad } & <19 años & 3 & 2 & 1 & 6 \\
\hline & 20-29 años & 21 & 15 & 15 & 51 \\
\hline & $>30$ años & 14 & 10 & 12 & 36 \\
\hline \multirow{4}{*}{$\begin{array}{l}\text { Nivel } \\
\text { educativo }\end{array}$} & Sin estudios & 7 & 1 & 1 & 9 \\
\hline & Primarios & 20 & 7 & 8 & 35 \\
\hline & Secundarios & 8 & 7 & 9 & 24 \\
\hline & Universitarios & 3 & 12 & 10 & 25 \\
\hline \multirow[t]{2}{*}{ Procedencia } & Autóctono & 15 & 6 & 13 & 34 \\
\hline & $\begin{array}{l}\text { Migración } \\
\text { interna }\end{array}$ & 23 & 21 & 15 & 59 \\
\hline \multirow{2}{*}{$\begin{array}{l}\text { Nivel } \\
\text { ocupacional }\end{array}$} & Básico & 28 & 13 & 15 & 56 \\
\hline & Intermedio & 10 & 14 & 13 & 37 \\
\hline \multicolumn{2}{|c|}{ TOTAL } & 38 & 27 & 28 & 93 \\
\hline
\end{tabular}

3 El proceso de codificación de los datos estuvo asistido por el software Atlas.ti 8.

4 Segmentos de los datos en bruto que pueden ser analizados aisladamente y en los que se hallan cuestiones clave en la verificación teórica. 
Tabla 2. La emergencia de la categoría central

\begin{tabular}{|c|c|c|c|}
\hline Códigos sustantivos & $\begin{array}{l}\text { Códigos } \\
\text { conceptuales }\end{array}$ & $\begin{array}{l}\text { Procesos Sociales } \\
\text { Básicos }\end{array}$ & $\begin{array}{l}\text { Categoría } \\
\text { central }\end{array}$ \\
\hline $\begin{array}{l}\text { DESARROLLO INDUSTRIAL: } \\
\text { NORTE DE MARRUECOS }\end{array}$ & & & $\begin{array}{l}\text { Respuestas } \\
\text { migratorias }\end{array}$ \\
\hline $\begin{array}{l}\text { - Actores } \\
\text { o Empresas manufactureras } \\
\text { de exportación (EME) } \\
\text { o Gobernanza pública } \\
\text { o Trabajadores del sector } \\
\text { industrial } \\
\text { o Otros }\end{array}$ & $\begin{array}{l}\text { Apuesta guberna- } \\
\text { mental por situar al } \\
\text { país en las CGV }\end{array}$ & $\begin{array}{l}\text { EME como } \\
\text { facilitadoras } \\
\text { del proceso } \\
\text { migratorio }\end{array}$ & $\begin{array}{l}\text { a la } \\
\text { privación } \\
\text { relativa }\end{array}$ \\
\hline $\begin{array}{l}\text { - Espacio industrial } \\
\text { transfronterizo } \\
\text { o Planes de desarrollo } \\
\text { o Inversión Extranjera Directa } \\
\text { o Infraestructura industrial y } \\
\text { de transporte }\end{array}$ & $\begin{array}{c}\text { Maximización de } \\
\text { beneficios por las } \\
\text { EME }\end{array}$ & $\begin{array}{l}\text { EME como } \\
\text { elemento }\end{array}$ & \\
\hline $\begin{array}{l}\text { - Espacio migratorio } \\
\text { transfronterizo } \\
\text { o Presión demográfica } \\
\text { o Transformación urbana } \\
\text { o Encarecimiento del coste de } \\
\text { vida } \\
\text { o Desarrollo humano } \\
\text { insuficiente }\end{array}$ & $\begin{array}{c}\text { Búsqueda del } \\
\text { bienestar en las EME }\end{array}$ & $\begin{array}{c}\text { segmentador } \\
\text { de la población } \\
\text { activa }\end{array}$ & \\
\hline \multicolumn{4}{|l|}{ CONDICIONES LABORALES } \\
\hline $\begin{array}{l}\text { - EME } \\
\text { o Tipo } \\
\text { o Rama industrial } \\
\text { o Categoría profesional }\end{array}$ & $\begin{array}{c}\text { Escaso control } \\
\text { guberna-mental en } \\
\text { el cumplimiento del } \\
\text { Código de Trabajo: } \\
\text { precariedad }\end{array}$ & $\begin{array}{c}\text { EME como } \\
\text { impulsoras de la } \\
\text { brecha de género }\end{array}$ & \\
\hline $\begin{array}{l}\text { - Seguridad/salud laboral } \\
\text { o Contrato laboral/extinción } \\
\text { o Salario/uso } \\
\text { o Vacaciones } \\
\text { o Jornada laboral/descanso } \\
\text { o Sindicalización }\end{array}$ & $\begin{array}{l}\text { Abundante mano de } \\
\text { obra descualificada } \\
\text { y feminizada: } \\
\text { aumento de la } \\
\text { competencia laboral }\end{array}$ & & \\
\hline
\end{tabular}


Tabla 2. La emergencia de la categoría central (Continuación)

\begin{tabular}{l} 
CULTURA MIGRATORIA DE LOS \\
TRABAJADORES \\
- Contexto familiar/personal \\
o Características \\
sociodemográficas \\
o Condiciones sociolaborales y \\
económicas \\
o Origen/cultura familiar y \\
personal \\
o Situación doméstica \\
o Redes familiares/de amistad \\
- Migración interna (MI) / \\
externa-internacional (ME) \\
o Motivaciones/causas \\
o Estrategias/obstáculos \\
o Remesas \\
- Papel de las EME en la \\
migración \\
o Atracción de mano de obra: MI \\
o Frustración de expectativas: \\
ME \\
o Paso previo a la ME \\
o Trampolín para la ME \\
o Redes de capital social \\
\hline
\end{tabular}

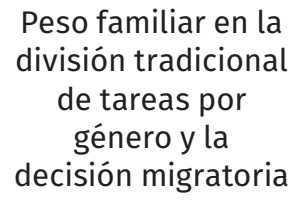

Respuestas

migratorias

a la privación relativa

\section{DESARROLLO INDUSTRIAL Y MIGRACIÓN EN EL NORTE DE MARRUECOS: LOS TRABAJADORES DE LAS EMPRESAS MANUFACTURERAS DE EXPORTACIÓN}

\section{La empresa manufacturera de exportación como facilitadora del proceso migratorio}

La gobernanza pública, en su apuesta por atraer IED a Marruecos, implementó una serie de políticas entre las que se encontraba el Código de Trabajo de 2004. Con esta normativa, que regula las condiciones laborales de los trabajadores del sector industrial, entre otros, se buscaba visibilizar entre la comunidad internacional los esfuerzos del país en el cumplimiento de los derechos laborales. La aprobación de este marco legislativo, sin embargo, supuso un dilema (Trinidad et al., 2018): hacer efectiva la normativa (implicaría una pérdida de competitividad para la atracción de IED) o no hacerla (supondría un debilitamiento de las condiciones laborales de los trabajadores). Ante esta disyuntiva, la gobernanza pública ha optado por una estrategia de permisividad: «Hay fábricas muy buenas [...] que dan derechos a todos los trabajadores. Pero en las demás no hay nada. Solamente explotan a la gente» ( $\left(\right.$ /37/S/2/AL/Khénifra ${ }^{5}$ ). Como corroboran Trinidad et al. (2018), a pesar de la existencia de diferencias según el tipo de EME, la rama industrial o la categoría profesional de los

\footnotetext{
5 Género (ㅇ, 3), edad, estado civil (S-soltero, C-casado, 0-otros), nivel educativo (0-sin estudios, 1-primarios, 2-secundarios, 3-universitarios), rama industrial en la que trabaja/trabajó (CO-confección, AU-automoción, AL-agroalimentación y transformación de productos del mar, CC-call center, OT-otros) y localidad de origen del entrevistado/a.
} 
trabajadores, el escaso control en la aplicación de la legislación ha supuesto, con carácter general, una precarización de las condiciones laborales.

Esta flexibilidad y precariedad, inherente al empleo en las EME, lleva implícita un proceso dialéctico en el imaginario de los trabajadores: por un lado, el miedo al despido (necesidad de trabajar y obtener ingresos), por otro, la frustración de las expectativas (negación de las aspiraciones de mejora). Frente a este conflicto, con importantes repercusiones en el curso vital, la cultura migratoria entra en acción: unas veces orientando hacia la emigración, otras en sentido inverso (el arraigo comunitario). Los trabajadores que disfrutan de mejores condiciones laborales, como los supervisores, los técnicos o los obreros de empresas de primera línea ${ }^{6}$, muestran un mayor rechazo a la idea de emigrar al extranjero: «Actualmente no [emigraría]. Por la estabilidad en el trabajo. Me gusta mi trabajo, me gusta mi profesión» (§/30/C/1/OT/Tánger). Alcanzar una estabilidad laboral supone que prevalezca una cultura migratoria centripeta, aunque inicialmente la posición fuera la contraria: «Si no hubiera encontrado las condiciones adecuadas, creo que habría sido mi sueño ir al extranjero» ( + /19/S/1/AU-AL/Kenitra).

El hecho de disponer de unas condiciones laborales acordes con la legislación, sin embargo, no es suficiente para cubrir las expectativas de otros trabajadores. La cultura migratoria centrífuga es más firme entre quienes contemplan la tenencia de un contrato de trabajo en las EME como una oportunidad para emigrar legalmente a Europa (Hennebry et al., 2019). La normativa española permite a los ciudadanos marroquíes con contrato en origen cumplir con los requisitos para la obtención de un visado de corta duración ${ }^{7}$. De este modo algunos trabajadores, que son tomados como referentes a seguir, acaban prolongando deliberadamente su estancia en destino más allá del tiempo de permiso. Hablaríamos de una situación de irregularidad sobrevenida: «Muchos de la empresa donde trabajo se fueron. Les daban vacaciones y pedían sus visados. Y de allí emigraban [...] Ese visado caducaba, tenía una validez de quince o veinte días, pero no volvían» ( $\delta / 28 / S / 3 / A L / O u e z z a n e)$. Las EME se han convertido en un «trampolín indirecto» para la emigración de sus trabajadores.

Pero no todos pueden organizar su estrategia migratoria en torno al visado. Los obstáculos para acogerse a una vía legal o los escasos recursos para el viaje, supondrán que otros trabajadores opten por continuar empleándose en las EME: «Para sacar el visado en el consulado te piden los tres meses de los boletines de pago, iy nosotros no tenemos nómina! ¡Nos pagan el dinero en sobre!» ( $\mathrm{J} / 33 / \mathrm{C} / 2$ / CC/Tánger); "como piden visado y tantas cosas complicadas, me he quedado aquí [...] lo de emigrar así por así, al azar, no. Eso no es para mí» ( $§ / 25 / S / 2 / C C / T e t u a ́ n)$. El arraigo comunitario también prevalecerá para quienes poseen cargas familiares, más habitual en trabajadores casados y con hijos: "Antes tenía ganas de ir a España y no

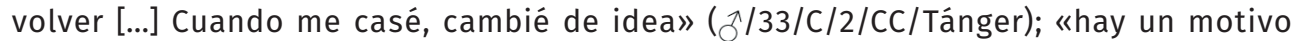
para permanecer en Marruecos: yo quiero quedarme cerca de mi familia, para verlos siempre» ( $Q / 23 / \mathrm{S} / 2 / \mathrm{AU} /$ Taunat).

En otras ocasiones los impedimentos para emigrar legalmente, especialmente entre los jóvenes, solteros y con menores cargas, no harán más que reorientar su estrategia migratoria hacia otras vías como, por ejemplo, la falsificación documental, los matrimonios de conveniencia o la emigración clandestina: "Conocimos a un hombre que estaba haciendo negocios de contratos [...] Mi hermana le pagó diez mil euros y se fue a España con todos los papeles arreglados» ( $\curvearrowright / 28 / \mathrm{S} / 1 / \mathrm{CO} / \mathrm{Beni}$ Ahmed). La frustración de las expectativas generada en su empleo, unido a otros

6 Las empresas de primera línea son aquellas multinacionales extranjeras que se identifican con su nombre matriz y se ubican, bien en una zona franca, bien en un polígono industrial. Frente a estas se sitúan las subcontratas y los talleres clandestinos, ambas con peores condiciones laborales para sus trabajadores.

7 Entre los documentos exigidos destaca la acreditación de la situación profesional que, para los asalariados, se evidencia mediante los certificados originales de empleo, los tres últimos justificantes originales de pago a La Caisse Nationale de Sécurité Sociale y las tres últimas nóminas (Consulado de España en Tánger, 2017). 
factores culturales que empujan hacia la emigración, reforzará la cultura migratoria centrífuga: «¡Por culpa de estas empresas que no nos dan nuestros derechos! ¡Eso me llevó a pensar en emigrar y trabajar en Europa! La familia que tengo allí me cuenta que trabajan bien y el salario es bueno. Y traen coches, compran casas aquí y consiguen un futuro mejor» ( $\delta / 29 / S / 1 / O T / T a ́ n g e r)$. Del mismo modo, algunos trabajadores que emigraron desde sus localidades de origen para emplearse en las EME, reorientan sus intenciones migratorias hacia el extranjero en lugar de hacia el retorno: "Las personas que perdieron su trabajo no volvieron a sus ciudades de origen [...] se fueron al extranjero» ( $\widehat{\delta} / 34 / \mathrm{S} / 3 / \mathrm{AU} /$ Tánger).

\section{La empresa manufacturera de exportación como elemento segmentador de la población activa}

Las EME instaladas en el norte de la región se han especializado en actividades que requieren un uso intensivo del factor trabajo: "Cada una [empresa] tiene un límite de personal. Pero en general hay un montón de personas [...] son batallones de personas» ( $\$ / 34 / \mathrm{C} / 1 / \mathrm{CO} /$ Casablanca); "En la automoción y el textil a lo mejor puede haber 200 o 300 trabajadores en cada empresa» ( $\$ / 27 / S / 1 / C O / T a z a)$. Si bien el número de empleados varía según la rama industrial o el tipo de EME, el sistema de producción en cadena hace habitual que se reclute a un importante volumen de trabajadores para el desarrollo de tareas simples, rutinarias y manuales: «Tenemos actualmente tres cadenas. Y cada cadena se compone de unos 30 trabajadores [...] Unos 100 en total» ( $(2 / 20 / \mathrm{S} / 2 / \mathrm{CO} / \mathrm{Fez})$. Para la atracción de estas empresas en territorio marroquí ha sido necesario disponer de una abundante mano de obra, la cual se ha cubierto mediante la afluencia de migrantes internos.

Esta disponibilidad laboral se visto favorecida por las dificultades económicas y laborales en las localidades de origen ${ }^{8}$, las cuales han forzado a muchos individuos a "migrar a los crecientes barrios marginales en las ciudades más grandes" (Davis, 2006, p. 100): «¿El motivo para venir a Tánger? Que no hay trabajo, no hay ingresos allí. En Fez ves las cafeterías llenas, pero nada de trabajo» $(\delta / 27 / \mathrm{C} / 0 / \mathrm{CO} / \mathrm{Fez})$. Frente a sus regiones de origen, Tánger y Tetuán son contempladas como lugares donde prosperar a través del empleo en las EME: «Los empleados en la industria vienen de todo Marruecos: Ifren, Layun, Jenifra, Fez, Fegig, Beni Malal, Uxda [...] En Tánger, la verdad, es que hay trabajo pero con sufrimiento» (o/29/S/2/AU/Meknes). Estos nuevos trabajadores se suman a los autóctonos, aumentando considerablemente la competencia laboral en las ciudades.

La población autóctona, sin embargo, difícilmente puede competir con los migrantes internos. Las oportunidades laborales de los primeros se ven limitadas ante la preferencia de las EME por emplear mano de obra foránea: «Algunas empresas prefieren hacer trabajar a esa gente que viene de lejos. A mí me ha pasado. Una vez fui con mi currículum y el jefe no ha visto nada. Únicamente me ha preguntado si soy tangerino» ( $\delta / 27 / S / 3 / C C / T a ́ n g e r)$. Las EME, de cara a reducir sus costes laborales, priorizan la contratación de aquellos trabajadores dispuestos a emplearse bajo peores condiciones. La necesidad de adquirir rápidamente ingresos con los que responder a las obligaciones familiares en origen, supone que los trabajadores procedentes del ámbito rural muestren un menor rechazo frente a situaciones de precariedad: "Ves la mala situación de tus padres, de la casa. Estás obligada a emigrar, a ayudarles, a trabajar en lo que sea» ( $+/ 27 / \mathrm{S} / 1 / \mathrm{AU} /$ Khénifra). En cambio, la seguridad que ofrece residir cerca de la familia y poseer un mayor capital social hará que la población autóctona sea más proclive a reclamar mejores condiciones y salarios: «Ellos [inmigrantes] aceptan

8 Las tasas de desempleo alcanzan su mayor cota entre la población joven. En l'Oriental, región emisora de población hacia Tánger-Tetuán-Alhucemas, la tasa de desempleo entre 15-24 años supera el 30\% (Haut-Commissariat au Plan, 2017). 
cualquier condición aunque sea miserable. Nosotros los tangerinos no [...] porque gracias a Dios trabajamos y vivimos cerca de nuestros padres» ( $\lambda / 27 / \mathrm{S} / 3 / \mathrm{CC} /$ Tánger). De esta manera se produce una dualización del mercado laboral (Piore, 1977) entre autóctonos e inmigrados, además de cierto rechazo de los primeros hacia los segundos: «¡Vienen del campo a trabajar a mitad de precio! [...] Y luego dicen que los jóvenes de Tetuán no quieren trabajar. ¡Sí quieren! ¡Pero con un salario digno!» ( + /45/C/0/CO/Tetuán).

El aumento de la mano de obra disponible, en definitiva, supone un descenso de las oportunidades laborales de los autóctonos. Frente a la inestabilidad laboral y los periodos de desempleo derivados de dicha coyuntura, emerge la idea de emigrar: "La juventud sufre este problema: el pobre hombre que pide un trabajo y le dicen que no [...] Muchos piensan entonces en emigrar» ( $Q / 34 / \mathrm{C} / 1 / \mathrm{CO} /$ Casablanca). La cultura migratoria centrífuga, sin embargo, no es exclusiva de los trabajadores autóctonos (Hennebry et al., 2019). Tanto ellos como los provenientes de la migración interna conviven diariamente con una precariedad laboral que promueve una percepción positiva hacia la emigración: "Cuando no encuentras trabajo y se cierran todas las puertas, uno se queda sentado y entonces piensa en emigrar a Europa» ( $\lesssim / 23 / S / 2 /$ CO/pueblo tetuaní).

\section{La empresa manufacturera de exportación como impulsora de la brecha de género}

Al igual que en la maquiladora mexicana, donde las mujeres ocupan los empleos de menor calidad (Solís et al., 2018), sucede en Tánger-Tetuán-Alhucemas. El acceso de la figura femenina a las EME acrecienta la mano de obra disponible, limitando las oportunidades laborales de los varones (Massey et al., 1993). Las EME demandan un perfil de trabajador (joven, poco cualificado, con urgencia de ingresos) que es exitosamente cubierto mediante la población femenina (Barajas y Martínez, 2013): «Es una empresa de producción, que requiere tareas manuales [...] y son más las mujeres» ( $\hat{\delta} / 25 / \mathrm{S} / 3 / \mathrm{AL} /$ Casablanca). Las obreras, muchas provenientes de la migración interna, son menos propensas a reivindicar sus derechos respecto a los hombres. En caso de algún conflicto relativo a sus condiciones laborales, las obligaciones familiares junto al fuerte sistema patriarcal vigente hará que sean menos exigentes: «Mujeres más. Porque tienen más paciencia aunque el salario sea bajo. Intentan sobrevivir» ( $/$ /29/S/2/AU/Meknes). Como argumentan los supervisores en las fábricas, las mujeres tienden a caracterizarse por ser "más dóciles; en cambio los hombres son más exigentes" (Solís, 2010, p. 68). Esta brecha de género supondrá que las EME opten por emplear más a las mujeres: «Más mujeres [...] [porque] aceptan el SMIG ${ }^{9}$, no como los hombres que no les parece suficiente» ( $Q / 23 / S / 1 / A U /$ Khénifra); «No contratan a más hombres porque saben [dirección empresarial] que pueden responder [...] Las mujeres, ¡las pobres!, no. Bajan la cabeza y callan» (q/25/S/0/CO/ Tánger). En la rama de la confección, por ejemplo, las mujeres suponen el $70 \%$ del total de trabajadores (Sales y Piñeiro, 2011).

Las mujeres empleadas en las EME, como se ha mencionado, no solo proceden de la propia ciudad: «En la fábrica de corte y confección en la que estaba [...] la mayoría eran mujeres que venían de ciudades pequeñas del sur de Marruecos, donde no hay trabajo [...] para mantener a sus familias» ( $\lesssim / 29 / 0 / 3 / C O / T a ́ n g e r)$. Las familias campesinas que poseen un pedazo de tierra colectiva o disponen de unos mínimos medios para producir alimentos, intentan "conservar su modo de vida enviando a sus hijas a trabajar a las fábricas de las ciudades industriales para completar los ingresos familiares" (Sales et al., 2012, p. 20). Estas mujeres jóvenes y escasamente cualificadas se convierten en el miembro de la familia más capacitado para adaptarse al contexto laboral en destino: las EME. Pese al todavía enérgico peso de la cultura patriarcal en el

9 Salario Mínimo Interprofesional Garantizado, situado en los 13,46 dírhams/hora (Ministère du Travail du Maroc, 2015). 
país alauí, las mujeres paulatinamente se van incorporado a los circuitos migratorios como mecanismo de solidaridad familiar: "Cuando tenía 18 años estaba viendo que no iba a llegar a lo que quería, ni mejorar la situación de mi familia [...] [Mi hermana y yo] hemos convencido a nuestro padre y hemos venido aquí [Tánger]. Aunque ellos [padres] tenían miedo» ( $q / 27 / S / 1 / A U / K h e ́ n i f r a)$.

Mientras que la cultura migratoria interna-centrífuga ha tenido gran incidencia en las mujeres, la internacional ha calado más intensamente en los varones. Los hombres, como figura de autoridad, son quienes tradicionalmente asumen el rol de proveedores: «El hombre piensa en emigrar [internacionalmente] más porque suele llevar esa responsabilidad de la familia [...] Para traer dinero y mejorar la situación» (Q/20/S/2/ $\mathrm{AU}-\mathrm{CO} /$ Midelt). Las expectativas de las mujeres empleadas en las EME, en cambio, transcurren más por casarse y dejar de trabajar: «Nada me permite dejar el trabajo. Solo si me casase, si viniera un buen chico que me hace no trabajar, pero así [soltera con cargas familiares] estoy obligada a trabajar» ( $Q / 27 / \mathrm{S} / 1 / \mathrm{AU} / \mathrm{Khé}$ ifra). La emigración no entra en sus planes, pues es una cuestión socialmente relegada al ámbito de actuación masculino: «¿Emigrar? ¡No! [...] Quiero un cambio: no seguir trabajando [...] Quiero que mi marido trabaje y yo ser ama de casa» ( $Q / 30 / \mathrm{S} / 1 / \mathrm{CO}-\mathrm{AL} /$ pueblo tetuaní). Incluso en aquellas con una actitud positiva hacia la emigración, esta idea queda aparcada al chocar con su interiorizado deber de ayuda familiar, basado en un sistema patriarcal de relaciones sociofamiliares: «Por supuesto que pienso en emigrar [internacionalmente], pero no puedo [...] porque tengo a mi madre sola y mis hermanos. Mi hermano es todavía pequeño y depende de mí» ( $/ / 18 / \mathrm{S} / 1 / \mathrm{CO} / \mathrm{El}$ Jebha). El comportamiento migratorio de estas mujeres, enmarcado en un contexto tradicional-conservador, queda relegado a la figura del esposo (o la familia), bien emigrando junto a él, bien mediante una posterior reagrupación familiar: «como chica soltera no puedo [emigrar internacionalmente]. Sí me iría si estoy con un marido» ( $+/ 27 / S / 1 /$ CO/Meknes).

Hoy día los efectos de la cultura migratoria centrífuga todavía inciden más entre los hombres (Heering et al., 2004). Sin embargo, como sucede en el caso mexicano (Woo, 2001), son cada vez más mujeres quienes, alejadas de la figura masculina, van ordenando sus aspiraciones vitales hacia fuera del país alauí. El peso normativo ejercido por instituciones como la familia, si bien aún muy presente, va perdiendo poco a poco importancia en la configuración del comportamiento social entre las generaciones más jóvenes: «Mi hermana que se fue [al extranjero] trabajaba también en la confección. No te voy a mentir [...] en nuestra familia no ven bien que una chica emigre» ( $Q / 25 / \mathrm{S} / 0 / \mathrm{CO} /$ Tánger); "La mujer suele tener problemas en Marruecos solo con dormir fuera de casa, ipues imagínate si emigra! Pero últimamente la mujer también emigra [internacionalmente], iy mucho!» ( $\delta / 32 / S / 2 / A L / T a ́ n g e r)$. Teniendo en cuenta que la mano de obra femenina es la que mayor subordinación y precariedad padece en las EME (Soriano et al., 2016), la frustración generada también actuará como impulso migratorio en algunas de ellas: "Oigo a compañeras jóvenes que quieren emigrar clandestinamente. Dicen que alli [Europa] es mejor aunque, ¡dios nos libre!, sea limpiando aseos. Al menos tienen dignidad, derechos [...] Aquí tienen su trabajo y lo dejan por el sufrimiento, el malestar y no tener nada» ( $Q / 27 / S / 1 / C O /$ Meknes). Pese a las convenciones sociales, que presionan hacia el arraigo comunitario, entre las nuevas generaciones se observa un incipiente deseo de emigración por sí mismas en concordancia con el denominado proceso de individualización social (Bauman, 2001; Beck y Beck-Gernsheim, 2002): «ahora las chicas jóvenes también quieren ir a Europa» ( $\lesssim / 29 / S / 1 / O T / T a ́ n g e r)$. El mismo resultado alcanzaron Heering et al. (2004), quienes sostienen que aquellas mujeres marroquíes con un trabajo remunerado y que juzgan negativamente su situación financiera tienen mayores intenciones de emigrar. La migración de las mujeres, como sugieren Aderghal y Berriane (2013), se ha convertido en un rasgo vigente de la emigración marroquí. 


\section{La incipiente sociedad de consumo como promotora de la sensación de privación relativa}

La presión demográfica en las principales ciudades de la región ha supuesto que la disponibilidad inmobiliaria se torne insuficiente. Los demandantes, cada vez más numerosos, han disparado el precio de la vivienda (incluido de alquiler), a la vez que se encarece el suelo urbanizable: «Antes las cosas eran un poco más baratas, pero ahora está todo caro, como el alquiler [...] ¡Hay mucha gente ya!» (o/36/C/1/CO/ Tánger). Teniendo en cuenta que buena parte de los obreros que se emplean en las EME lo hacen a cambio de unos salarios que, en el mejor caso, alcanzan el SMIG, el encarecimiento residencial no hace más que empujarlos hacia viviendas antiguas, pobremente equipadas y ubicadas en las zonas más desfavorecidas de la urbe: «La casa acabamos de comprarla. Nos hemos dejado la piel para comprarla [...] ¡lba a derrumbarse! No estaba bien construida. ¡Pero es lo que hay!» ( $\$ / 27 / S / 1 / C O / T a z a)$. Además, las expectativas de poder adquirir una vivienda en propiedad, especialmente presente entre los autóctonos y la población foránea asentada, les son negadas: «nos gustaría tener una casa pero el salario no nos lo permite, apenas se pierde en los gastos [...] En Tánger la vida es muy cara» ( $Q / 27 / \mathrm{S} / 1 / \mathrm{AU} /$ Khénifra). En 2014 solamente uno de cada dos habitantes en el ámbito urbano de la región $(56,7 \%)$ residía en una vivienda en propiedad (Haut-Commissariat au Plan, 2016b).

Para los nuevos residentes llegados de todo el país la situación es aún más inestable: las opciones residenciales pasan por el hacinamiento. El elevado coste de los alquileres hace habitual la convivencia de un importante número de personas sin vínculo familiar en una misma habitación y vivienda: «la mayoría de gente que viene del sur vive en Tánger en barrios pobres, donde hay robos, drogas [...] Hay un montón de chicas solteras que vienen, alquilan un piso y viven como latas de sardinas [...] con una pequeñita cocina y el váter fuera en las escaleras» ( $\lesssim / 33 / C / 2 / C C /$ Tánger). Estos migrantes internos tienden a residir junto a compañeros de trabajo de su mismo género: "Somos seis chicas y todas trabajamos [en la industria]. La casa tiene tres habitaciones y en cada habitación hay dos chicas» ( $q / 29 / \mathrm{S} / 2 / \mathrm{AU} /$ Meknes). La situación residencial, unida a la precariedad laboral, genera un ambiente de exclusión en el que afloran sentimientos de inferioridad social entre la población inmigrante (Zoubir, 1997). La frustración de las expectativas en las EME los empuja hacia la idea de que su éxito, personal y familiar, solo podrá ser alcanzado en el extranjero: «prefiero ir fuera [extranjero] a trabajar duro y conseguir un sueldo que pueda satisfacer mis necesidades que quedarme aquí [Tánger]» (q/27/S/3/AU/Meknes).

El encarecimiento del coste de vida también se refleja en otros gastos relativos al hogar: "Tengo que trabajar porque hay que pagar el alquiler, la electricidad, el agua,... ¡la vida es muy cara en Tánger!» ( $\$ / 37 / \mathrm{S} / 2 / \mathrm{AL} /$ Khénifra). El precio de estos servicios, junto con el desembolso dedicado a la vivienda y la alimentación, hacen que los trabajadores difícilmente puedan destinar parte de su salario al ahorro, ayudar a la familia o acceder a bienes de consumo y estilos de vida similares a Europa: "Sí tengo [intención de emigrar] por causa del dinero [...] Mi familia vive una situación económica difícil. Las oportunidades de trabajo son escasas. El sueldo es muy bajo y no te ayuda a hacer gran cosa» ( $\lesssim / 22 / \mathrm{S} / 1 / \mathrm{AU} / \mathrm{Fez}$ ). Los bajos sueldos en las EME (Kopinak et al., 2019) dificultan el cumplimiento de estas expectativas vitales, estimulando las intenciones migratorias de los trabajadores: «El SMI en Marruecos no supera los 2.000 dírhams, es decir, 200 euros. Y tú ves a otro que regresa los veranos y se gasta 1.000 euros o más delante de ti en una sola semana [...] Tú eres el primero que sueña con eso» ( $\$ / 31 / 0 / 1 / C O / T a ́ n g e r)$. En otros casos la cultura migratoria orienta en sentido inverso. El apego familiar, especialmente presente entre casados con hijos, hace que se apueste por la incorporación de la esposa al mercado laboral: «La mujer es imposible quedarse sin trabajar en Tánger. Porque el salario de su marido no va 
a ser suficiente para poder vivir aquil» ( $Q / 37 / \mathrm{C} / 2 / \mathrm{AU} /$ Khenifra). Pese a las reticencias a que la mujer trabaje, las mayores oportunidades laborales de ellas facilitan su acceso laboral: «Hay que pagar alquiler, agua, gastos de los niños, comida,... Nosotros [marroquíes] teníamos un principio: que la mujer no trabaja [...] Y hemos llegado a que la mujer sale a trabajar» (§̊/47/C/1/OT/Tetuán).

Pese a todo, es entre los obreros con estudios secundarios y universitarios donde más incidencia tiene la cultura migratoria centrífuga. En ellos, identificados con una baja consideración de status (en terminología weberiana), la sensación de privación relativa será elevada: «el trabajo no anima, no les convence o no es acorde con lo que han estudiado. Entonces trabajan para ahorrar dinero [...] y marcharse» ( $\delta / 25 / \mathrm{S} / 3 /$ $\mathrm{AL} /$ Casablanca). Los puestos de trabajo que las EME demandan son mayoritariamente aquellos que no exigen cualificación (Mendoza, 2011), por lo que las posibilidades de acceder a un empleo y un salario acorde con su nivel educativo son bajas: «los puestos que te pueden brindar una comodidad económica en la empresa de exportación son escasos» ( $($ /28/S/3/AU/Sefrou). Las redes de apoyo disponibles o la urgencia de ingresos, entre otros aspectos, harán que unos no puedan más que optar por la sobrecualificación, mientras otros rechazan emplearse en las EME: «Hay un montón de trabajos [...] [pero] aquí lo que estudias, no lo vas a trabajar» ( $1 / 27 / \mathrm{S} / 3 / \mathrm{CC} /$ Tánger). Además, la preferencia de algunas EME por contratar a trabajadores no cualificados, menos proclives a reclamar mejoras, dificulta el acceso laboral a la población con estudios superiores. Según datos del Haut-Commissariat au Plan (2016a) para la población urbana de Tánger-Tetuán-Alhucemas, la tasa de desempleo asciende a mayor nivel educativo: el $9,5 \%$ entre quienes no tienen estudios frente al $21,8 \%$ y el $23,7 \%$ de aquellos con estudios medios y superiores. La cultura migratoria orientará a estos "exiliados del agobio» (Varela, 2013) hacia una posición positiva hacia la emigración: «Emigran por [...] la crisis de la gente que tiene un alto nivel de estudios. Tengo una amiga que [...] tiene una licenciatura en empresariales y está trabajando en una fábrica como cualquier otro trabajador normal. ¿Dónde están esos estudios? Sinceramente, es algo que me pone de los nervios» ( $+/ 20 / \mathrm{S} / 2 / \mathrm{AU}$-CO/Midelt).

La debilidad del sistema público de seguridad social, en comparación con Europa, tampoco ayuda a los trabajadores a alejarse de la idea de emigrar: «nos dicen que hay trabajo en Europa, y eso de la jubilación, el paro y la sanidad. Dan más cosas

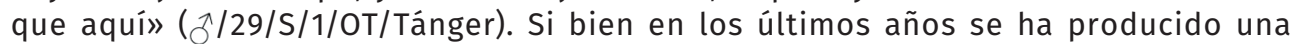
profunda reforma en materia de protección sociolaboral, con hitos como el derecho de prestación por desempleo ${ }^{10}$ (desde 2014) o la mejora de las infraestructuras sanitarias, la cobertura continúa siendo insuficiente ante los problemas de la ciudadania: "quisiera tener la sanidad cubierta, un mes de vacaciones completo y buenas condiciones de trabajo» ( $\lesssim / 29 / 0 / 3 /$ CO/Tánger). La tasa de mortalidad infantil fue en 2015 del 23,7\%o (frente al 3,5\%o de Francia y España) y el gasto público en salud en 2014 se situó en el 2,0\% del PIB (el 9,0\% en Francia y el 6,4\% en España) (United Nations, 2016). Como advierte Aixlà (2009, p. 252) "Marruecos tiene un sistema sanitario público con enormes deficiencias por la baja inversión estatal".

\section{CONCLUSIONES}

El proceso de desarrollo industrial en el norte de Tánger-Tetuán-Alhucemas ha vivido en la última década su mayor apogeo con hitos como la ampliación del puerto Tanger Med o la apertura de Tanger Automotive City. En este proceso se han asentado numerosas empresas manufactureras de exportación (EME) que han permitido la colocación de más de un millar de trabajadores (Haut-Commissariat au Plan, 2016a), sumándose los relativos a las empresas auxiliares. En este contexto se ha desarrollado

10 La Indemnité pour Perte d'Emploi. Sin embargo, no puede exceder del SMIG y los seis meses de retribución. 
el presente trabajo, cuyo interés se ha centrado en analizar la influencia que las EME han ejercido en la decisión de emigrar (o no) de sus trabajadores. Para alcanzar tal propósito, el artículo ha optado por desarrollar una estrategia metodológica en la que destaca, como procedimiento analítico, la Teoría Fundamentada. Siguiendo esta metodología, el código «Respuestas migratorias a la privación relativa» ha emergido como categoría central. A partir de dicha categoría, la Figura 2 sintetiza las distintas estrategias de los trabajadores.

Figura 2. Respuestas migratorias a la privación relativa

\begin{tabular}{|c|c|c|}
\hline \multirow[b]{2}{*}{$\begin{array}{c}\text { La búsqueda del } \\
\text { bienestar a través } \\
\text { de la migración } \\
\text { interna }\end{array}$} & $\begin{array}{c}\text { Bienestar asociado } \\
\text { a la familia }\end{array}$ & \multirow[b]{2}{*}{$\begin{array}{l}\text { La búsqueda del } \\
\text { bienestar a través } \\
\text { del arraigo } \\
\text { comunitario }\end{array}$} \\
\hline & & \\
\hline $\begin{array}{c}\text { Empresas no respetuosas } \\
\text { con el Código de Trabajo }\end{array}$ & & $\begin{array}{c}\text { Empresas respetuosas } \\
\text { con el Código de Trabajo }\end{array}$ \\
\hline \multirow[t]{2}{*}{$\begin{array}{c}\text { La búsqueda del } \\
\text { bienestar a través } \\
\text { de la migración } \\
\text { internacional }\end{array}$} & & $\begin{array}{l}\text { La búsqueda del } \\
\text { bienestar a través de la } \\
\text { promoción laboral en la } \\
\text { empresa manufacturera } \\
\text { de exportación }\end{array}$ \\
\hline & $\begin{array}{c}\text { Bienestar asociado } \\
\text { al individuo }\end{array}$ & \\
\hline
\end{tabular}

Las EME se han especializado en actividades productivas que requieren un uso intensivo del factor trabajo. Buena parte de esos puestos se han cubierto mediante trabajadores procedentes de la migración interna, especialmente mujeres jóvenes. Las dificultades económicas en origen han impulsado su migración hacia las grandes urbes del norte, con la esperanza de emplearse en unas empresas que demandan un perfil laboral idóneo para ellas (escasa cualificación y poca exigencia en las condiciones de trabajo). Las mujeres se han incorporado progresivamente a los circuitos migratorios internos como mecanismo de solidaridad familiar.

El empleo en las EME, sin embargo, se aleja frecuentemente de las aspiraciones ubicadas en él. La gobernanza pública ha optado por una estrategia de permisividad en el control de la legislación laboral, suponiendo una precarización general de las condiciones laborales. Además, la elevación de la presión demográfica en las ciudades ha ocasionado una inflación de precios que choca con los habituales bajos salarios. La sensación de privación relativa de muchos trabajadores hará que la búsqueda del bienestar se traslade hacia la migración internacional. La arraigada cultura migratoria reforzará sus intenciones, especialmente en varones, jóvenes, solteros y con pocas cargas familiares. Asimismo las EME se han articulado como facilitadoras del proceso migratorio: disponer de un contrato laboral permite, en el caso de España, cumplir los requisitos para obtener un visado de corta duración. En las mujeres, sus intenciones pasan por casarse y dejar de trabajar. Pero entre las nuevas generaciones, con una mentalidad más abierta y moderna, son más 
quienes ordenan sus aspiraciones vitales hacia el exterior, anticipando el bienestar individual al familiar.

La frustración de expectativas que genera las EME no siempre orienta hacia la salida del país. El arraigo comunitario y el apego familiar prevalecerá sobre el bienestar individual entre quienes poseen cargas familiares, más habitual en trabajadores adultos, casados y con hijos. La cultura migratoria centrífuga se impondrá en ellos. Por último, quienes se emplean en condiciones laborales respetuosas con legislación, tienden a orientar su búsqueda del bienestar mediante la promoción laboral en las propias EME. Por ello supervisores y técnicos o los obreros de empresas de primera línea, se alejan del fenómeno migratorio.

En síntesis, el proceso de industrialización en el norte de Marruecos ha tenido una relevante incidencia en la cultura migratoria de la región. En concreto, las EME 1) han facilitado el proceso migratorio de sus trabajadores (convirtiéndose en un «trampolín indirecto» para la emigración); 2) se han articulado como elemento segmentador de la población activa (entre autóctonos y migrantes internos); 3) han impulsado la brecha de género (mediante la feminización de mano de obra); y 4) han promovido una sensación de privación relativa (los bajos salarios imposibilitan responder a la incipiente sociedad de consumo). Mientras que en algunos trabajadores prevalece la cultura migratoria centrífuga (emigración internacional), en otros lo hará la cultura migratoria centrípeta (arraigo comunitario).

\section{FINANCIACIÓN}

Proyecto CSO2013-40646-P, financiado por el Ministerio de Economía y Competitividad.

\section{REFERENCIAS}

Aderghal, M. (2014). Discours, images et opinions sur l'émigration au Maroc. En M. Berriane (Edit.), Marocains de l'extérieur 2013 (pp. 139-158). Rabat: Fondation Hassan II.

Aderghal, M., \& Berriane, M. (2013). Morocco-Europe Relations through the Image of the Other. Antwerp: EUMAGINE.

Aixlà, Y. (2009). Mujeres, reproducción y contracepción en Marruecos. En J. Comelles et al. (Edits.), Migraciones y salud (pp. 251-264). Tarragona: Universidad Rovira i Virgili.

Barajas, M., y Martínez, M. (2013). Los procesos de relocalización industrial en dos espacios fronterizos: México y Marruecos. En M. Barajas, y M. Solís (Edits.), Fronteras comparadas (pp. 47-86). Tijuana: Colegio de la Frontera Norte.

Barros, F. (2017). Inmigración y mercado de trabajo en España: los Trabajadores Marroquíes Procedentes de la Industria Exportadora. Granada: Universidad de Granada.

Bauman, Z. (2001). The Individualized Society. Cambridge: Polity.

Beck, U., \& Beck-Gernsheim, E. (2002). Individualization: Institutionalized Individualism and its Social and Political Consequences. London: Sage.

Berriane, M. (2014). Images et perceptions de l'Europe par la société marocaine à travers le prisme des droits de l'Homme. En M. Berriane (Edit.), Marocains de l'extérieur 2013 (pp. 159-187). Rabat: Fondation Hassan II. 
Berriane, M. (2018). Introduction générale. En M. Berriane (Edit.), Marocains de l'extérieur 2017 (pp. 11-27). Rabat: Fondation Hassan II.

Bianchi, E., y Szpak, C. (2013). Cadenas globales de producción. Buenos Aires: OMC Flacso. Bourdieu, P. (2012). La distinción. Madrid: Taurus.

Bustamante, J. (1983). Maquiladoras: A New Face of International Capitalism on Mexico's Northern Frontier. En J. Nash, \& M. Fernández-Kelly (Edits.), Women, Men and the International Division of Labor (pp. 224-256). Albany: SUNY Press.

Capote, A. (2014). Apuntes sobre el desasosiego entre la juventud marroquí. Documents d'Anàlisi Geogràfica, 60(2), 237-259. https://doi.org/10.5565/rev/dag.94

Carrero, V., Soriano, R., y Trinidad, A. (2012). Teoría fundamentada. Madrid: Centro de Investigaciones Sociológicas.

Carrillo, M. (1990). Maquiladoras y migración en México. Puebla: Consultoría Económica.

Castles, S. (2004). Why migration policies fail. Ethnic and Racial Studies, 27(2), 205-227.

Cohen, J., \& Sirkeci, I. (2011). Cultures of Migration. Austin: University of Texas.

Consulado de España en Tánger. (2 de octubre de 2017). Solicitudes de visado (en línea). Recuperado el 16 de marzo de 2020, de sitio web de Ministerio de Asuntos Exteriores, Unión Europea y Cooperación: https://bit.ly/2rd14op

Davis, D. (2006). Neoliberalism, Environmentalism, and Agricultural Restructuring in Morocco. The Geographical Journal, 172(2), 88-105. http://www.jstor.org/stable/3873982

De Haas, H. (2006). North African migration systems. Migración y Desarrollo, 7, 65-95.

De Haas, H. (2007). The Impact of International Migration on Social and Economic Development in Moroccan Sending Regions. Oxford: International Migration Institute.

Dekker, R., \& Engbersen, G. (2013). How Social Media Transform Migrant Networks and Facilitate Migration. Global Networks, 14(4), 401-418. https://doi.org/10.1111/glob.12040

Echeverría, M., y Lewin-Fischer, P. (2016). Jóvenes con intención de salir. Península, 11(2), 9-33. https://doi.org/10.1016/j.pnsla.2016.08.001

Engbersen, G., Snel, E., \& Van Meeteren, M. (septiembre de 2013). Declining migration from Morocco to the Netherlands and the diminutive causation of migration. The International Migration Institute Working Papers Series, (173). Recuperado el 16 de marzo de 2020, de https://bit.ly/2x5kz5j

Fernández-Kelly, M. (1983). Mexican Border Industrialization, Female Labor Force Participation and Migration. En J. Nash, M. Fernández-Kelly (Edits.), Women, Men, and the International Division of Labor (pp. 205-223). Albany: SUNY Press.

Fussell, E. (2004). Sources of Mexico's Migration Stream. Social Forces, 82(3), 937-967. http://doi.org/10.1353/sof.2004.0039

García, Á., y Jordán, J. (2006). El proceso de privatización y las reformas económicas en Marruecos. Barcelona: CIDOB.

García, J., y Verdú, A. (2008). Imaginarios sociales sobre migración. Papers, 89, 81-101. https://doi.org/10.5565/rev/papers/v89n0.749 
Gendreau, M., y Giménez, G. (2002). La migración internacional desde una perspectiva sociocultural. Migraciones Internacionales, 1(2), 147-178. http://www.scielo.org.mx/ $\mathrm{pdf} / \mathrm{migra} / \mathrm{v} 1 \mathrm{n} 2 / \mathrm{v} 1 \mathrm{n} 2 \mathrm{a} 6 . \mathrm{pdf}$

Gereffi, G., \& Sturgeon, T. (2013). Global value chain-oriented industrial policy. En D. Elms, P. Low (Edits.), Global value chains in a changing world (pp. 329-360). Ginebra: World Trade Organization.

Haut-Commissariat au Plan. (2016a). Annuaire Statistique. Région Tanger-Tetouan. Tánger: HCP.

Haut-Commissariat au Plan. (2016b). Indicateurs RGPH2014. Recuperado el 16 de marzo de 2020, de http://rgphentableaux.hcp.ma/

Haut-Commissariat au Plan. (2017). Annuaire statistique. Région l'Oriental. Rabat: HCP.

Hawkins, B., Minjares, Y., Harris, L., \& Rodríguez, J. (2010). Values in conflict: youth in a Culture of Migration. En W. Cornelius et al. (Edits.), Mexican Migration and the U.S. Economic Crisis (pp. 161-184). San Diego: University of California.

Heering, L., Van der Erf, R., \& Van Wissen, L. (2004). The Role of Family Networks and Migration Culture in the Continuation of Moroccan Emigration. Journal of Ethnic and Migration Studies, 30(2), 323-337. https://doi.org/10.1080/1369183042000200722

Hennebry, J., Barros, F., \& Kopinak, K. (2019). Moving to stay or staying to move? En A. Trinidad et al. (Edits.), Localized Global Economies on the Northern Borderlands of Mexico and Morocco (pp. 181-209). Cham: Palgrave Macmillan.

Hennebry, J., Kopinak, K., Soriano, R., Trinidad, A., \& Hondagneu-Sotelo, P. (2014). From «Khadema» to «Zemegria». En M. Walton-Roberts, J. Hennebry (Edits.), Territoriality and Migration in the E.U. Neighbourhood (pp. 65-81). Heidelberg: Springer.

Jolivet, D. (2015). Times of uncertainty in Europe: migration feedback loops in four Moroccan regions. The Journal of North African Studies, 20(4), 553-572. https://doi.org /10.1080/13629387.2015.1065041

Kopinak, K. (2011). How Maquiladora industries contribute to Mexico-U.S. labor migration. Papers, 96(3), 633-655. http://doi.org/10.5565/rev/papers/v96n3.238

Kopinak, K., \& Soriano, R. (2013). Types of Migration Enabled by Maquiladoras in Baja California. Journal of Borderlands Studies, 28(1), 75-91. http://doi.org/10.1080/088656 55.2012 .751733

Kopinak, K., Quintero, C., \& Hennebry, J. (2019). Working Conditions in Border Export Industries and Migration. En A. Trinidad et al. (Edits.), Localized Global Economies on the Northern Borderlands of Mexico and Morocco (pp. 115-152). Cham: Palgrave Macmillan.

Kopinak, K., Soriano, R., Trinidad, A., Hondagneu-Sotelo, P., \& Hennebry, J. (2013). A transatlantic comparison of the impact of production for export on international migration. En M. Barajas, M. Solís (Edits.), Fronteras comparadas (pp. 119-150). Tijuana: Colegio de la Frontera Norte.

Massey, D., Arango, J., Hugo, G., Kouaouci, A., Pellegrino, A., \& Taylor, J. (1993). Theories of International Migration. Population and Development Review, 19(3), 431-466. http:// doi.org/10.2307/2938462

Mata, D. (2015). Ways of Staying Put in Ecuador. Journal of Ethnic and Migration Studies, 41(14), 2274-2290. http://doi.org/10.1080/1369183X.2015.1053850 
Mendoza, J. (2011). Aspectos económicos de la migración en la frontera norte de México y en el Magreb. En N. Ribas (Edit.), El Río Bravo Mediterráneo (pp. 147-172). Barcelona: Bellaterra.

Ministère du Travail du Maroc. (2015). Salaire minimum. Recuperado el 16 de marzo de 2020, de sitio web de Ministère du Travail et de l'Insertion Professionnelle du Maroc: https://bit.ly/2YZZ8ju

Ojeda, A., y Espinosa, D. (2010). Afrontamiento y Autocontrol en Adolescentes Michoacanos: Evaluando su Alternativa de ¿Migrar o no Migrar?. Interamerican Journal of Psychology, 44(1), 168-175. https://www.redalyc.org/articulo.oa?id=28420640018

Pennell, C. (2009). Breve historia de Marruecos. Madrid: Alianza.

Piore, M. (1977). The dual labor market. En D. Gordon (Edit.), Problems in Political Economy (pp. 93-97). Lexington: DC Heath.

Portes, A. (1979). Illegal Immigration and the International System, Lessons from Recent Legal Mexican Immigrants to the United States. Social Problems, 26(4), 425-438. https://doi.org/10.2307/800506

Sadiqi, F. (2007). Intentions, Causes, and Consequences of Moroccan Migration. Fiesole: Robert Schuman Centre.

Sales, A., y Piñeiro, E. (2011). La moda española en Tánger. Barcelona: SETEM.

Sales, A., Carrión, J., y Fernández, F. (2012). Tratados de Libre Comercio y derechos laborales. En M. Vargas, B. Brennan (Edits.), Impunidad S.A. (pp. 14-45). Barcelona: Observatorio de la Deuda en la Globalización.

Seligson, M., Williams, E. (1981). Maquiladoras and Migration. Austin: University of Texas.

Serajuddin, U., \& Verme, P. (2015). Who is Deprived? Who Feels Deprived? Labor Deprivation, Youth and Gender in Morocco. Review of Income and Wealth, 61(1), 140-163. http://hdl. handle.net/10986/9326

Snel, E., Engbersen, G., \& Faber, M. (2016). From Bridgeheads to Gate Closers. En O. Bakewell et al. (Edits.), Beyond Networks (pp. 134-155). London: Palgrave Macmillan.

Solís, M. (2010). La construcción simbólica de un mercado de trabajo feminizado en la ciudad de Tánger. Frontera Norte, 22(43), 55-80. http://www.scielo.org.mx/scielo. php?script=sci_arttext\&pid=S0187-73722010000100003\&lng=es\&nrm=is

Solís, M., y Castañeda, M. (2013). Jóvenes en la confección: trayectorias laborales y expectativas de vida en la frontera. En M. Barajas, M. Solís (Edits.), Fronteras comparadas (pp. 87-118). Tijuana: Colegio de la Frontera Norte.

Solís, M., Trinidad, A., y Soriano, R. (2018). Mercados de trabajo en regiones fronterizas y no fronterizas de México. Estudios Fronterizos, 19(38), 1-29. http://doi.org/10.21670/ ref.1811011

Soriano, R., Trinidad, A., y Kopinak, K. (2015). Los efectos de los Programas de Ajuste Estructural en la desigualdad social interna. Praxis Sociológica, 19, 15-38. https:// dialnet.unirioja.es/servlet/articulo?codigo=5383976

Soriano, R., Trinidad, A., Kopinak, K., \& Hennebry, J. (2016). The symbolic place of female workers in the borderland export industry. En M. Solís (Ed.), Gender Transitions Along Borders (pp. 57-70). Abingdon: Routledge. 
Stark, O., \& Taylor, J. (1989). Relative Deprivation and International Migration. Demography, 26(1), 1-14. https://doi.org/10.2307/2061490

Timmerman, C., De Clerck, H., Hemmerechts, K., \& Willems, R. (2014). Imagining Europe from the Outside. En N. Chaban, M. Holland (Edits.), Communicating Europe in Times of Crisis (pp. 220-247). London: Palgrave Macmillan.

Trinidad, A., Soriano, R., \& Barros, F. (2018). Working conditions in the export industry of northern Morocco: Legal framework and situation on the ground. International Labour Review, 157(2), 337-361. https://doi.org/10.1111/ilr.12108

Trinidad, A., Soriano, R., Barros, F., Kopinak, K., \& Hennebry, J. (2015). The Localized Global Economy in Northern Morocco. Revista Española de Investigaciones Sociológicas, 152, 101-122. https://doi.org/10.5477/cis/reis.152.121

United Nations. (2016). Human Development Report. Nueva York: United Nations.

United Nations. (2019a). Human Development Indicators-Morocco. Recuperado el 16 de marzo de 2020, de http://hdr.undp.org/en/countries/profiles/MAR

United Nations. (2019b). International migrant stock. Recuperado el 16 de marzo de 2020, de https://bit.ly/2NutxAU

Varela, A. (2013). Por el derecho a permanecer y a pertenecer. Pamplona: Traficantes de sueños.

Woo, O. (2001). Las mujeres también nos vamos al Norte. Guadalajara: Universidad de Guadalajara.

World Bank. (2020). DataBank-Morocco. Recuperado el 29 de marzo de 2020, de sitio web de World Bank: https://data.worldbank.org/country/morocco

Zabin, C., \& Hughes, S.(1 de junio de 1995). Economicintegration and laborflows. International Migration Review, 29(2), 395-422. https://doi.org/10.1177\%2F019791839502900204

Zoubir, C. (1997). Migraciones internas contemporáneas y dinámica social al nordeste marroquí. Cuadernos de Relaciones Laborales, 10, 103-117. https://revistas.ucm.es/ index.php/CRLA/article/view/CRLA9797120103A

\section{NOTA BIOGRÁFICA}

Francisco Barros Rodríguez es Licenciado en Sociología y en Ciencias del Trabajo. Doctor en Ciencias Sociales por la Universidad de Granada (becado por el programa FPU del Ministerio de Educación). Profesor del Departamento de Organización de Empresas, Marketing y Sociología de la Universidad de Jaén. Miembro del grupo de investigación Problemas Sociales en Andalucía (SEJ129). Visiting Researcher en el International Migration Institute (IMI) de la Universidad de Oxford (Reino Unido) y en el Migration and Employment Research Centre (MERC) del Trinity College de Dublín (Irlanda). Últimas publicaciones (en coautoría): artículo "Employment conditions in the export industry of northern Morocco" (International Labour Review, 2018), capítulo "Moving to stay or staying to move? Borderlanders \& internal migrants negotiating work and mobility in export processing areas of Tijuana and Tangier-Tétouan" (Palgrave Macmillan, 2019) y capitulo "The world in one click: Emerging social problems associated with e-commerce in Southern Europe" (Edward Elgar, 2020). 
Rosa M. Soriano Miras es Profesora Titular del Departamento de Sociología (UGR). Premio Nacional del CES de tesis doctoral (2004). Miembro del Instituto de la Migraciones. Secretaria de la Facultad de CC.PP. Políticas y Sociología (UGR) desde 2016. Vicepresidenta de la Asociación Andaluza de Sociología desde 2018. Pertenece al programa de Doctorado en Estudios Migratorios de la UGR, y al de Ciencias Sociales y Derecho de la UNED. Último proyecto de investigación "Deslocalización industrial y pautas de compra de prendas de vestir en el norte global. Los casos de Europa y Norteamérica" BBVA. Principal línea de investigación: migración, globalización, interseccionalidad e investigaciones multisituadas. Últimas publicaciones: co-editora del libro Localized Global Economies on the Northern Bordelands of México an Morocco en la editorial Palgrave (2019); The Well-Being of Moroccan Immigrants in Spain: A Composite Indicator (2019) en Social Indicators y Water resources and textile maquilas in Tehuacán (2019) en International Journal of Water Resources Development.

Antonio Trinidad Requena es doctor en Sociología por la Universidad de Granada. En la actualidad es Catedrático de Sociología de la Universidad de Granada y Director del Grupo de Investigación "Problemas Sociales en Andalucía". Tiene reconocidos 4 tramos de investigación y 1 de transferecia. Entre sus últimas publicaciones se encuentran los libros Localized Global Economies on the Northern Borderlands of Mexico and Morocco; Teoría fundamentada "Grounded Theory". La construcción de la teoría a través del análisis interpretacional; Leer la sociedad y La realidad económica y social de las personas mayores. Gran parte de sus trabajos versan sobre problemas sociales, imnigración y evaluación de organizaciones y programas, materia sobre la que ha realizado numerosas publicaciones, entre ellas Employment conditions in the export industry of northern Morocco. Legal framework and situation on the ground; Evacuación de programas de intervención social y Evaluación diagnóstica de los Planes Autonómicos sobre drogas. 